Original article

\title{
Inhaled Corticosteroid phobia among parents of Egyptian asthmatic children
}

\author{
Amira SA. Said ${ }^{a, b, *}$, Nadia Hussain ${ }^{c}$, Lamiaa N. Abdelaty ${ }^{\text {d }}$, Amal HI. Al Haddad ${ }^{\text {e }}$, \\ Abdullah Abu Mellal ${ }^{\mathrm{f}}$ \\ a Department of Clinical Pharmacy, College of Pharmacy, Al Ain University, Al Ain, Abu Dhabi, United Arab Emirates \\ ${ }^{\mathrm{b}}$ Department of Clinical Pharmacy, Faculty of Pharmacy, Beni Suef University, Beni Suef, Egypt \\ ${ }^{c}$ Department of Pharmaceutical Sciences, College of Pharmacy, Al Ain University, Al Ain, Abu Dhabi, United Arab Emirates \\ d Department of Clinical Pharmacy, Faculty of Pharmacy, October 6 University, Egypt \\ e Cambridge Medical and Rehabilitation Center, Al Ain, Abu Dhabi, United Arab Emirates \\ ${ }^{\mathrm{f}}$ College of Health and Human Sciences, Charles Darwin University, Darwin, Northern Territory, Australia
}

\section{A R T I C L E I N F O}

\section{Keywords:}

Asthma

Corticosteroid

Phobia

Children

\begin{abstract}
A B S T R A C T
Background: Inhaled Corticosteroid therapy is the cornerstone of asthma treatment. Yet, the reported prevalence of steroid phobia among parents of asthmatic children has been concerning. This study aimed to assess the impact of steroid phobia on ICS adherence, and asthma management.

Method: A multicenter, cross-sectional study was held among 500 parents of asthmatic children over 12-months. Each participant completed a structured questionnaire that recorded patients' demographic data, and explored participants' main concerns regarding ICS. Additionally, participants level of asthma control was assessed by the Arabic childhood asthma control test C-ACT.

Result: Of 500 interviewed asthmatic children, up to $66.6 \%$ reported having ICS fears, yet only $25.8 \%$ reported discussing their concerns with their healthcare providers. In addition, over $50 \%$ of parents reported requesting ICS sparing. Regarding ICS adherence, a significant difference $(<0.001)$ was reported as $33.3 \%$ vs $40.1 \%$ for concerned and non-concerned parents respectively. Participants with ICS fears had children with significantly $(<0.001)$ lower mean C-ACT scores of $33.3 \%$ versus $46.7 \%$ for those with no fear, respectively. In addition, Request for ICS sparing was reported as $61.5 \%$ vs $53.9 \%$ for concerned and non-concerned parents respectively. However, asthma severity and discussing ICS concerns was not significantly affected by ICS fear.

Conclusion: This study suggests that steroid phobia is a significant factor that influence ICS adherence and asthma control. Proper asthma education should be targeted to alleviate unjustifiable steroid use concerns. Future research should be more oriented to crafting proper interventional strategies to better address the ICS negative perceptual barriers
\end{abstract}

\section{Introduction}

Asthma is one of the most prevalent of chronic diseases, particularly in children. Asthma has become a global healthcare challenge that affects more than 339 million people worldwide. A number that is expected to further increase in the coming years by additionally 100 million people. ${ }^{1}$ Despite ongoing advances in asthma management, it still poses a significant burden on healthcare resources due to persistent poor asthma control. Uncontrolled childhood asthma is significantly burdened by decreased quality of life, asthma morbidity, higher hospitalizations rates, multiple emergency visits and even death. Up to 250,000 death case from asthma have been reported by WHO mainly in low and middle income countries. ${ }^{2}$

Current worldwide Epidemiological studies strongly suggest a persistent concerning increase in asthma prevalence especially among the pediatric population. However, the causes behind this rise is yet unknown. In Egypt, the prevalence of asthma among Egyptian children aged $3-15$ years was estimated to be $8.2 \% .^{3}$

It is well recognized that asthma is an incurable disease with persistent airway inflammation. Therefore, the contemporary pattern of

\footnotetext{
* Corresponding author. Department of Clinical Pharmacy, Al Ain University, P.O. Box: 64141, Al Ain, Abu Dhabi, United Arab Emirates.

E-mail address: amira.ahmed@aau.ac.ae (A.SA. Said).
} 
asthma control is mainly based on managing the inflammatory portion of the disease. This has been greatly achieved through ICS administration which is so far considered the first-line and the most effective therapy in all asthma treatment guidelines. ${ }^{4}$ The clinical value of corticosteroids in controlling asthma has long been recognized to effectively suppress airways inflammation, improve asthma control and reduce exacerbations. ${ }^{5}$ Unfortunately, in real practice, adherence is a patient choice, where non-adherence may hamper asthma control and heavily burdens healthcare resources.

Improving patients' adherence in practice has always been challenging as reasons for non-adherence are highly variable, complex and some may not be even modifiable. The most common reported barriers to ICS adherence include; fears of side effects, or patients' non-belief in medication benefits or necessity. It is well reported that patients ICS phobia has largely restricted its usefulness and efficacy. ${ }^{6}$

Several raised related ICS concerns such as growth suppression, weight gain, bone weakness, addiction and psychiatric disturbances have been shown to be merely misconceptions with no evidence base. ${ }^{7}$ Strategies of managing asthma should go far beyond the availability of effective medications to more focus on patient education about the indispensable part of ICS in asthma management. Targeting patients own perception and behaviors towards ICS is a detrimental factor in deciding asthma therapy adherence and success. ${ }^{8}$

\subsection{Aim of the work}

The aim of this study was to address the factors that may contribute to parents steroid fear and assess its impact on ICS adherence, asthma control and severity in pediatric asthmatic patients. Identifying these factors would help to develop more interventional strategies to overcome steroids irrational fears and favor a significant improvement in asthma management.

\section{Methodology}

\subsection{Ethical approval}

Approval for the study was sought from the Research Ethics Committee of Faculty of Medicine, Beni-Suef University, Egypt. All participants provided written informed consent prior to study enrolment where they were assured that all the gathered data will be for research purposes only. The study design was in line with the requirements of revised Helsinki declaration of 1964 (revised 2013). The study was conducted from March 2019 till March 2020.

\subsection{Population and setting}

This is a multicenter, cross-sectional study that was held over a 12month-period among parents of asthmatic children aged 1-16 years old. All recruited asthmatic patients were being treated at the outpatient clinics of four general hospitals and two university hospitals. These hospitals were located in three different cities of Egypt; Beni-Suef, Al Fayoum, and El Minya. Personal interviews were conducted in Arabic by the researcher for each participant. The sample size was calculated by using Epi info software and the minimum sample size was determined as 384 with $95 \%$ confidence interval, $50 \%$ prevalence and $\alpha=0.05$. A convenient sample of 500 asthmatic children was collected and studied.

\subsection{Inclusion criteria}

All recruited participants included asthmatic children who were prescribed ICS and whose asthma diagnosis, assessment and control were conducted according to GINA guidelines. In all cases, asthma diagnosis and ICS use was confirmed by the physician treating the patient and by the patient medical records.

\subsection{Exclusion criteria}

All children of other respiratory illnesses or history of corticosteroids treatments for reasons other than asthma were excluded from the study.

\subsection{Questionnaire development}

A structured questionnaire from previous literature was adapted and utilized for this study. The questionnaire was conveniently distributed to parents of asthmatic children attending different asthma clinics in $\mathrm{Al}$ Fayoum, Al Minya, and Beni-Suef hospitals. This study focused on these particular cities since they are underdeveloped and often underrepresented in research in comparison to other main cities in Egypt. Convenience sampling was used in this study for its simplicity, easiness, and for rapid collection of data in a cost effective way. The questionnaire was conducted by personal interviews. The researchers approached each participant where after self-introduction, they briefly explained the study objectives.

Participants were asked to anonymously complete the questionnaire while waiting for their turn in consultation. Each participant handled his response back on the spot to the researcher in the provided sealed envelope.

The questionnaire collected data such as parents and children age, sex, socioeconomic status, asthma severity, parents' education level, asthma belief, health education, asthma control, severity and ICS adherence. In addition, the questionnaire investigated parents' main concerns and their main source of information regarding ICS.

The level of asthma control was assessed by requesting participants to complete the previously validated translated Arabic C-ACT to assess asthma control. ${ }^{9}$ The Arabic childhood asthma control test C-ACT is composed of seven questions (four child-reported and three parent-reported). A score $>19$ and a score $\leq 19$ indicates controlled asthma, and uncontrolled asthma respectively. Non-adherence to ICS was defined as not using the controller for $\geq 6$ days/week. All the described data were obtained in a single visit.

The Arabic childhood asthma control test C-ACT questionnaire was assessed for validity and reliability on a pilot sample of 20 participants. The internal consistency of the questionnaire was measured by Cronbach's Alpha and calculated to be 0.85 and the reliability coefficient was 0.82 .

\subsection{Data analysis}

All statistical analysis was conducted using SPSS version 23.0 (SPSS Inc., Chicago, IL, USA). Pearson's chi-square test was used to compare participants' characteristics with and without steroid phobia. Multivariable logistic regression analysis was performed to identify factors associated with steroid phobia. A P value of $<0.05$ was considered statistically significant.

\section{Results}

A total of 500 participants (164 males and 336 female) responded to the questionnaire. The participants' demographic details are summarized in Table 1. The recruited asthmatic children involved 226 males and 215 females. Of the participants; $20 \%, 41.2 \%$, and $38.8 \%$ belonged to low, middle and high socioeconomic levels respectively. Most parents' respondents, were college graduates $(74.8 \%)$, while the rest were either high school (12.2\%) or illiterate (13\%). Up to $37.4 \%$ and $10.2 \%$ of participants reported following up their children's asthma condition with pediatricians, and asthma specialists respectively, while $52.4 \%$ reported no follow up.

The severity of asthma in the recruited asthmatic children were reported as mild, moderate, and severe in $36.8 \%, 48.4 \%, 14.4 \%$ of participants, respectively. In this study, majority of the asthmatic children parents $(67.8 \%)$ believed that asthma is a chronic condition. Receiving 
Table 1

Effect of patient demographic and clinical characteristics on ICS Fear, $(n=500)$.

\begin{tabular}{|c|c|c|c|}
\hline Variable & $\begin{array}{l}\text { Patients with } \\
\text { ICS Phobia } \\
(\mathrm{n}=333)\end{array}$ & $\begin{array}{l}\text { Patients with no } \\
\text { phobia (167) }\end{array}$ & $P$ value \\
\hline $\begin{array}{l}\text { Children Gender } \\
\text { - Male } \\
\text { - Female }\end{array}$ & $\begin{array}{l}146(43.8) \\
187(56.1)\end{array}$ & $\begin{array}{l}80(47.9) \\
87(52.1)\end{array}$ & $<0.001$ \\
\hline $\begin{array}{l}\text { Parents Gender } \\
\text { - Male } \\
\text { - Female }\end{array}$ & $\begin{array}{l}128(38.4) \\
205(61.5)\end{array}$ & $\begin{array}{l}36(21.5) \\
131(78.4)\end{array}$ & $<0.001$ \\
\hline $\begin{array}{l}\text { Age distribution of } \\
\text { Interviewed Participant } \\
\text { (yr) } \\
-18-34 \\
-35-55 \\
->55\end{array}$ & $\begin{array}{l}181(54.4) \\
126(37.8) \\
8(2.4)\end{array}$ & $\begin{array}{l}104(62.3) \\
55(32.9) \\
8(4.8)\end{array}$ & $<0.001$ \\
\hline $\begin{array}{l}\text { Age distribution of Asthmatic } \\
\text { children (yr) } \\
-<5 \text { yr } \\
-5-10 y r \\
-11-16 y r\end{array}$ & $\begin{array}{l}58(17.4) \\
221(66.3) \\
54(16.2)\end{array}$ & $\begin{array}{l}15(8.9) \\
126(75.4) \\
26(15.6)\end{array}$ & $<0.001$ \\
\hline $\begin{array}{l}\text { Socioeconomic status } \\
\text { - Low } \\
\text { - Middle } \\
\text { - High }\end{array}$ & $\begin{array}{l}144(43.2) \\
146(43.8) \\
43(12.9)\end{array}$ & $\begin{array}{l}50(29.9) \\
60(35.9) \\
57(34.1)\end{array}$ & $<0.001$ \\
\hline $\begin{array}{l}\text { Interviewed Parents } \\
\text { Education Level } \\
\text { - College } \\
\text { - High school } \\
\text { - Illiterate }\end{array}$ & $\begin{array}{l}240(72.0) \\
51(15.3) \\
42(12.6)\end{array}$ & $\begin{array}{l}134(80.2) \\
10(6.0) \\
23(13.7)\end{array}$ & $<0.001$ \\
\hline $\begin{array}{l}\text { Interviewed Parents } \\
\text { Occupation } \\
\text { - Housewife } \\
\text { - Unemployed } \\
\text { - Employee } \\
\text { - Businessman } \\
\text { - Other }\end{array}$ & $\begin{array}{l}70(20.8) \\
29(8.63) \\
180(53.5) \\
35(10.4) \\
22(6.55)\end{array}$ & $\begin{array}{l}36(21.5) \\
15(8.9) \\
91(54.4) \\
16(10.7) \\
9(5.4)\end{array}$ & 0.36 \\
\hline $\begin{array}{l}\text { Asthma disease } \\
\text { - Acute } \\
\text { - Chronic }\end{array}$ & $\begin{array}{l}198(59.4) \\
135(40.5)\end{array}$ & $\begin{array}{l}98(58.6) \\
69(41.3)\end{array}$ & 0.528 \\
\hline $\begin{array}{l}\text { Asthma Health Education } \\
\text { - Yes } \\
\text { - No }\end{array}$ & $\begin{array}{l}123(36.9) \\
210(63)\end{array}$ & $\begin{array}{l}110(65.8) \\
57(34.1)\end{array}$ & $<0.001$ \\
\hline $\begin{array}{l}\text { ACT score } \\
\text { - Controlled } \\
\text { - Uncontrolled }\end{array}$ & $\begin{array}{l}110(33.3) \\
223(66.6)\end{array}$ & $\begin{array}{l}78(46.7) \\
89(53.2)\end{array}$ & $<0.001$ \\
\hline $\begin{array}{l}\text { Follow up with } \\
\text { - Asthma specialist } \\
\text { - Pediatrician } \\
\text { - No follow up }\end{array}$ & $\begin{array}{l}40(12.0) \\
133(39.9) \\
160(48.0)\end{array}$ & $\begin{array}{l}29(17.3) \\
57(34.1) \\
86(48.5)\end{array}$ & $<0.001$ \\
\hline $\begin{array}{l}\text { Use of controller medication } \\
\text { - Adherent } \\
\text { - Non-Adherent }\end{array}$ & $\begin{array}{l}112(33.3) \\
198(66.3)\end{array}$ & $\begin{array}{l}67(40.1) \\
100(59.9)\end{array}$ & $<0.001$ \\
\hline $\begin{array}{l}\text { Asthma severity } \\
\text { - Mild } \\
\text { - Moderate } \\
\text { - Severe }\end{array}$ & $\begin{array}{l}129(38.7) \\
149(44.7) \\
55(16.5)\end{array}$ & $\begin{array}{l}66(39.5) \\
75(44.9) \\
26(15.5)\end{array}$ & 0.45 \\
\hline $\begin{array}{l}\text { Discuss Concerns } \\
\text {-Yes } \\
\text { - No }\end{array}$ & $\begin{array}{l}82(24.6) \\
251(75.3)\end{array}$ & $\begin{array}{l}42(25.1) \\
125(74.8)\end{array}$ & 0.21 \\
\hline $\begin{array}{l}\text { Request ICS Sparing } \\
\text {-Yes } \\
\text { - No }\end{array}$ & $\begin{array}{l}205(61.5) \\
128(38.4)\end{array}$ & $\begin{array}{l}90(53.9) \\
77(46.1)\end{array}$ & $<0.001$ \\
\hline
\end{tabular}

asthma health education, was only reported by $46.6 \%$ of participants.

Overall, a high proportion of parents $(66.6 \%)$ reported having ICS fears, yet only $25.8 \%$ reported discussing these concerns with their healthcare providers. In addition, over $50 \%$ of parents reported requesting ICS sparing (59\%). In addition, $75.5 \%, 55.4 \%, 36 \%, 16.5 \%$, and $11.4 \%$ reported that their main source of information regarding ICS were physicians, pharmacists, Drug information leaflet, personal experience, and family/friends respectively.

Table 1 details the effect of patient characteristics on ICS Fear by comparing parents with steroid phobia (67.2\%) and those without
(32.8\%). Significant differences were observed between the groups in respect to gender of the child, age (parents and children), socioeconomic level, parents' education level, asthma health education, follow up.

In addition, regarding ICS adherence, a significant difference $(<0.001)$ was reported as $33.3 \%$ vs $40.1 \%$ for concerned and nonconcerned parents respectively. Interestingly, participants with ICS fears had children with significantly lower mean C-ACT scores than those with no fear (mean ACT scores were $33.3 \%$ versus $46.7 \%$, for concerned and non-concerned parents, respectively).

Additionally, ICS sparing was more significantly requested by concerned parents. Request for ICS sparing was reported as $61.5 \%$ vs $53.9 \%$ for concerned and non-concerned parents respectively.

On the other hand, asthma severity and discussing ICS concerns was not significantly affected by ICS fear. The percentage of mild, moderate, and severe asthma patients were 38.7 vs $39.5,44.7$ vs $44.9,16.5$ vs 15.5 for concerned and non-concerned parents respectively.

Table 2 investigated the causes of ICS fears among participants. The majority of participants feared dependence $(72.8 \%)$, while $63 \%, 57.8$, 55 , and $52.8 \%$ feared growth retardation, weight gain, osteoporosis, and need for larger doses, respectively. In addition, 39.8\% of participants reported fearing ICS with no specific causes of its concerns.

As shown in Table 3. The effect of source of information on ICS concern was investigated. The results showed that concerned parents significantly selected pharmacists ( $41.7 \%$ vs $13.7 \%)$ and family/friends ( $9 \%$ vs $2.4 \%$ ) as their main information source compared to nonconcerned parents, respectively. Whereas, non-concerned parents significantly selected physicians ( $55 \%$ vs $25.5 \%$ ), and personal experience $(10.8$ vs $5.7 \%)$ as their main information source compared to concerned parents, respectively (see Table 4).

A logistic multi-regression model was applied to further evaluate the factors associated with steroid phobia. According to the statistical results analysis, factors such as parents sex (female showed more significantly steroid phobia than males), health education, asthma control, adherence, and ICS sparing request were found to correlate with steroid phobia $(\mathrm{p}<0.001)$.

However, factors such as; asthma severity, discussing ICS concerns, and asthma belief (acute or chronic) was not correlated to steroid phobia.

\section{Discussion}

As per international guidelines, ICS is the mainstay treatment for managing persistent asthma in both adults and children. Despite ICS unquestionable benefits in improving asthma symptoms, asthma disease remains largely uncontrollable due to non-adherence especially in the pediatric population. ${ }^{10}$ Lack of adherence fueled by a strong negative perception about ICS requires healthcare providers to exert more efforts into counselling, educating and motivating asthmatic individuals and in the case of children, their guardians about the essential role of ICS in asthma management. Several studies have reported positive associations between ICS adherence and patients' beliefs. ${ }^{11}$

In the present study, $66.6 \%$ of participants reported ICS fear, and up

Table 2

Causes of ICS fears among participants, $(n=500)$.

\begin{tabular}{ll}
\hline Concern & No (\%) \\
\hline Still Concerned without causes & $199(39.8)$ \\
Weight Gain & $289(57.8)$ \\
Growth Retardation & $315(63)$ \\
Dependence & $364(72.8)$ \\
Need for larger doses & $275(55.0)$ \\
Osteoporosis & $264(52.8)$ \\
Cancer & $156(31.2)$ \\
Immunodeficiency & $260(52.0)$ \\
Organ toxicity & $142(28.4)$ \\
Psychological Problems & $266(53.2)$ \\
\hline
\end{tabular}


Table 3

Effect of information source on ICS concern, $(n=500)$.

\begin{tabular}{llll}
\hline Source & $\begin{array}{l}\text { Concerned parents } \\
(\mathrm{n}=333)\end{array}$ & $\begin{array}{l}\text { Non Concerned parents } \\
(\mathrm{n}=167)\end{array}$ & P Value \\
\hline $\begin{array}{l}\text { Drug Information } \\
\text { Leaflet }\end{array}$ & $60(18.1)$ & $30(17.9)$ & 0.24 \\
$\begin{array}{l}\text { Family/Friends } \\
\text { Personal }\end{array}$ & $30^{9}$ & $4(2.4)$ & $<0.001$ \\
$\quad \begin{array}{l}\text { experience } \\
\text { Physicians }\end{array}$ & $19(5.7)$ & $18(10.8)$ & 0.001 \\
Pharmacists & $85(25.5)$ & $92(55.0)$ & $<0.001$ \\
\hline
\end{tabular}

Table 4

Factors associated with steroid phobia.

\begin{tabular}{|c|c|c|}
\hline & Estimate, 95\% CI & P-Value \\
\hline \multicolumn{3}{|l|}{ Sex } \\
\hline Male & Reference & \\
\hline Female & $1.6(1.54-2.74)$ & $<0.001$ \\
\hline Age (y) & Reference & \\
\hline $18-34$ & $1.03(0.62-0.73)$ & 0.9 \\
\hline $35-55$ & $0.65(0.3-1.63)$ & 0.3 \\
\hline$>55$ & $0.97(0.96-1.17)$ & 0.5 \\
\hline Asthma Disease & Reference & \\
\hline Acute & $0.62(0.36-0.95)$ & 0.113 \\
\hline Chronic & $0.81(0.52-1.12)$ & 0.25 \\
\hline \multicolumn{3}{|c|}{ Asthma Health Education } \\
\hline Yes & Reference & \\
\hline No & $1.64(1.36-1.26)$ & $<0.001$ \\
\hline \multicolumn{3}{|l|}{ ACT score } \\
\hline Controlled & Reference & \\
\hline Uncontrolled & $1.54(1.16-2.06)$ & $<0.001$ \\
\hline Follow up With & Reference & \\
\hline Asthma Specialist & $1.08(0.82-1.22)$ & 0.125 \\
\hline Pediatrician & $1.1(0.63-1.85)$ & 0.7 \\
\hline No Follow up & $1.15(0.64-2.05)$ & 0.39 \\
\hline \multicolumn{3}{|c|}{ Use of controller medication } \\
\hline Adherent & Reference & \\
\hline Non-Adherent & $2.1(1.75-2.71)$ & $<0.001$ \\
\hline Asthma severity & Reference & \\
\hline Mild & $0.98(0.6-1.14)$ & 0.563 \\
\hline Moderate & $1.14(0.69-1.90)$ & 0.87 \\
\hline Severe & $0.7(0.21-2.33)$ & 0.72 \\
\hline Discuss Concerns & Reference & \\
\hline Yes & $1.3(1.02-1.76)$ & 0.1 \\
\hline No & $0.75(0.40-1.38)$ & 0.51 \\
\hline Request ICS Sparing & Reference & \\
\hline Yes & $1.46(1.12-1.9)$ & $<0.001$ \\
\hline No & & \\
\hline
\end{tabular}

to $61.5 \%$ of them requested ICS sparing. The results help to shed light on the problem of inhaled steroid fear among the parents of Egyptian children. Similarly, other previous studies in Egypt,${ }^{12}$ Canada, ${ }^{13}$ Turkey, and China ${ }^{14}$ have reported that up to $53 \%, 58.8 \%, 59 \%$, and $35 \%$ of participants feared ICS use, respectively.

Factors behind steroid fears in this study were, dependence (72\%), growth retardation (63\%), weight gain $(57.8 \%)$, osteoporosis $(52 \%)$, need for larger doses (55\%), immunodeficiency (52\%), or nonspecific concerns (39\%). Similarly, another study has shown similar ICS fears of addiction, tolerance or poor safety profiles. ${ }^{15}$

In addition, negative patients' perceptions about ICS in this study have probably caused concerned parents to significantly $(\mathrm{p}<0.001)$ request more ICS sparing, become less adherent with poorer asthma control compared to non-concerned ones. This is in line with a previous study that reported that patients ICS beliefs and fears were highly predictable for potential non-adherence in clinical settings. ${ }^{16}$ Consistently, another review study reported that patients with fewer medication concerns had twice the odds of being adherent, ${ }^{17}$ which further confirms that patient beliefs guide their adherence decision. Among existent strategies implemented to improve patients' adherence, modifying perceptual barriers was reported as the most effective strategy. ${ }^{18}$
This study has shown that parents ICS fears negatively reflected their children level of asthma control. This agrees with a previous study in a group of asthmatic children where suboptimal asthma control was associated with parents' concerns regarding ICS use. The study by Smith et al. and Walker et al. showed that deficiencies in asthma control are strongly correlated with potentially modifiable parental beliefs. These studies also showed that positive patients' conceptions were associated with improved clinical asthma outcomes. ${ }^{19,20}$ Another study among preschool asthmatic children have shown that concerned parents had lower odds of having their controlling medication at home $\mathrm{e}^{21}$

Interestingly, this study showed that less significantly $(\mathrm{p}<0.001)$ concerned parents ( $12.0 \%$ vs $17.3 \%$, and $39.9 \%$ vs $34.1 \%$ ) was noted for those who followed up with asthma specialist or pediatrician vs non concerned ones, respectively. In addition, less significantly concerned parents were noted for patients who followed with an asthma specialist compared to pediatricians $(12.0 \%$ vs $39.9 \%$; $p<0.001)$. This may be attributed to better asthma education with specialists compared to pediatricians. This complies with a previous Egyptian study that reported a significant correlation between physicians' qualification and proper asthma education and control. Patients followed up by specialists have shown better adherence while those followed up by general practitioners have shown more emergency visits ${ }^{22}$

It is of note in this study that lack of asthma health education was reported by $63 \%$ of concerned parents' vs $34.1 \%$ for non-concerned ones ( $\mathrm{p}<0.001$ ). Lack of proper patient education about asthma disease and treatments could be the driving force behind their negative perceptual fears. Research shows that appropriate asthma education provided to patients results in improved clinical outcomes ${ }^{23}$

The present study also showed that a large proportion of both concerned $(59.4 \%)$ and non-concerned parents (58.6\%) believed that asthma is an acute illness which further confirms their lack of proper knowledge regarding asthma. A previous study has reported up to $26 \%$ of Egyptian asthmatic children stopped using their ICS when asymptomatic due to their false belief that asthma is an acute condition. ${ }^{23}$ Similarly, a previous study has reported that up to $60 \%$ of asthmatic children parents thought that their children will outgrow the diagnosis and hence do not need proper follow up or maintenance therapy. ${ }^{24}$ Parents failure to understand asthma chronicity could impair successful asthma management with poor clinical outcomes. ${ }^{24}$

Addressing patients concerns and perceptual barriers to ICS should be prioritized as one of the key factors to improve patients' adherence and asthma control. This is consistent with a previous study that has shown that a collaborative asthma educational intervention has markedly improved parents asthma perceptions and adherence rates up to $92 \%{ }^{25}$ Another recent study reported that asthmatic children parents regular medical visits, communications and consultation positively influenced their intention to comply with their ICS. ${ }^{26}$

Based on the above raised issues, negative ICS beliefs can be considered as a potentially modifiable factor that can be rectified with proper interventional communications between patients and healthcare providers.

Patients educational approach should be multifaceted to not only improve patients' asthma knowledge but also to eliminate their misconceptions and fears concerning their medications.

However, there is little data on the specific educational programs needed to eliminate steroid phobia. Therefore, more future qualified studies should be targeted not only to assess the impact of steroid phobia on asthma management, but also to investigate the effective educational strategies that tackle steroid phobia and improve asthma management.

In summary, these study findings underline the significant impact that parental perceptions can have on their asthmatic children treatment adherence and control. Therefore, targeting modifying patients ICS fears and misconceptions should be highly considered when devising strategies to improve asthma management. 


\subsection{Limitations}

The present study has several limitations. First, a relatively small sample size was studied. In addition, using convenience sampling in this study may cause selection bias.

All patients collected data were limited by relying largely on child and parent self-report. Although The ACT test is a widely used to classify asthma control, it remains self-reported and highly subjective.

\section{Conclusion}

This study has shown that patient ICS fears was significantly associated with less patients' adherence and asthma control. Patients ICS concerns are rational fears that are misguided by misinformation. This indirectly suggests that steroid phobia is highly modifiable and can be rectified with appropriate, carer focused education in order to eliminate ICS unjustifiable concerns. Understanding patients' fears should provide a frame work for effective future strategies to better address negative perceptual barriers and improve their confidence in treatment and quality of life.

\section{Authors' contributions}

Amira SA Said: Concept, planning of study design, collected and analyzed data, manuscript preparation and review. Lamiaa N. Abdelaty: Data collection, Nadia Hussain, Amal Al Haddad Abdullah Abu Mellal: Manuscript review. All authors have critically reviewed and approved the final draft and are responsible for the content and similarity index of the manuscript.

\section{Funding}

This research received no specific grant from any funding agency in the public, commercial or not-for-profit sectors.

\section{Declarations of competing interest}

None.

\section{Acknowledgements}

The authors would like to thank the interviewers, children and parents who participated in the survey and helped to make this study successful.

\section{References}

1 Zahran HS, Bailey CM, Damon SA, Garbe PL, Breysse PN. Vital signs: asthma in children- United States, 2001-2016. Morb Mortal Wkly Rep. 2018;67(5):149-155.

2 Utidjian LH, Fiks AG, Localio AR, et al. Pediatric asthma hospitalizations among urban minority children and the continuity of primary care. J Asthma. 2017;54(10): 1051-1058.
3 Meatty E, ElDesoky T, ElDomyaty H, ElGilany A, Nasef N. Prevalence of childhood bronchial asthma and its associated factors: a community based study in Egypt. Prog Med Sci. 2018;2(2):14-20.

4 McCracken JL, Veeranki SP, Ameredes BT, Calhoun WJ. Diagnosis and management of asthma in adults a review. JAMA - Journal of the American Medical Association. 2017;318(3):279-290, 18

5 Bhagavatheeswaran K, Kasav J, Singh A, Mohan S, Joshi A. Asthma-related knowledge, attitudes, practices (KAP) of parents of children with bronchial asthma: a hospital-based study. Ann Trop Med Publ Health. 2016;9(1):23-30.

6 Lee JY, Her Y, Kim CW, Kim SS. Topical corticosteroid phobia among parents of children with atopic eczema in Korea. Ann Dermatol. 2015;27(5):499-506.

7 Hui RWH. Inhaled corticosteroid-phobia and childhood asthma: current understanding and management implications. Paediatr Respir Rev. 2020;33:62-66.

8 Hossny E, Rosario N, Lee BW, et al. The use of inhaled corticosteroids in pediatric asthma: Update. World Allergy Organization Journal. 2016;12(9):26.

9 AlTeneiji M, AlKalbani A, Nasser H, Iram D, Alblooshi A, Narchi H. Cross-sectional study assessing the performance of the Arabic translated childhood asthma control test. NPJ Prim care Respir Med. 2018;28:41.

10 Chong J, Haran C, Chauhan BF, Asher I. Intermittent inhaled corticosteroid therapy versus placebo for persistent asthma in children and adults. Cochrane Database Syst Rev. 2015;22(7):CD011032.

11 Klok T, Kaptein AA, Duiverman EJ, Brand PL. Long-term adherence to inhaled corticosteroids in children with asthma: observational study. Respir Med. 2015;109 (9):1114-1119.

12 Zedan MM, El Regal ME, Osman EA, Fouda AE. Steroid phobia among parents of asthmatic children: myths and truth. Iran J Allergy, Asthma Immunol. 2010;9(3): $163-168$.

13 Boulet LP. Perception of the role and potential side effects of inhaled corticosteroids among asthmatic patients. Chest. 1998;113(3):587-592.

14 Ip KI, Hon KL, Tsang KYC, Leung TNH. Steroid phobia, Chinese medicine and asthma control. Clin Res J. 2018;12(4):1559-1564.

15 Koster ES, Philbert D, Winters NA, Bouvy ML. Adolescents' inhaled corticosteroid adherence: the importance of treatment perceptions and medication knowledge. J Asthma. 2015;52(4):431-436.

16 Huurne KK Ter, Brusse-Keizer M, van der Valk P, Movig K, van der Palen J, Bode C. Patients with underuse or overuse of inhaled corticosteroids have different perceptions and beliefs regarding COPD and inhaled medication. Patient Prefer Adherence. 2018;12:1777-1783.

17 Cooper V, Metcalf L, Versnel J, Upton J, Walker S, Horne R. Patient-reported side effects, concerns and adherence to corticosteroid treatment for asthma, and comparison with physician estimates of side-effect prevalence: a UK-wide, crosssectional study. npj Prim Care Respir Med. 2015;25:15026.

18 Lycett H, Wildman E, Raebel EM, Sherlock JP, Kenny T, Chan AHY. Treatment perceptions in patients with asthma: synthesis of factors influencing adherence. Respir Med. 2018;141:180-189.

19 Smith LA, Bokhour B, Hohman KH, et al. Modifiable risk factors for suboptimal control and controller medication underuse among children with asthma. Pediatrics. 2008;122(4):760-769.

20 Walker HA, Chim L, Chen E. The role of asthma management beliefs and behaviors in childhood asthma immune and clinical outcomes. J Pediatr Psychol. 2009;34(4): 379-388.

21 Callaghan KJ, Riekert KA, Ruvalcaba R, Rand CS, Eakin MN. Medication beliefs are associated with not having controller medications available among head start children with asthma. Am J Respir Crit Care Med. 2017;2017:A2991, 195.

22 Salama AA, Mohammed AA, El Okda ESE, Said RM. Quality of care of Egyptian asthmatic children: clinicians adherence to asthma guidelines. Ital J Pediatr. 2010;36: 33.

23 Amer O, Morsy S. Underuse of controller medications in Egyptian asthmatic children. Egypt J Pediatr Allergy Immunol. 2013;11(1):29-34.

24 Parikh K, Paul J, Fousheé N, Waters D, Teach SJ, Hinds PS. Barriers and facilitators to asthma care after hospitalization as reported by caregivers, health providers, and school nurses. Hosp Pediatr. 2018;8(11):706-717.

25 Conn VS, Ruppar TM. Medication adherence outcomes of 771 intervention trials: systematic review and meta-analysis. Prev Med. 2017;99:269-276.

26 Tilly-Gratton A, Nadon MA, Houle A, Pelaez S, Ducharme FM. What convinces parents of children with asthma to adhere to maintenance inhaled corticosteroids? Can J Respir Crit Care, Sleep Med. 2018;2(3):147-154. 